\title{
Study on Clinical Presentation of Breast Carcinoma of 50 Cases
}

\author{
Mosammat Mira Pervin \\ Haradhan Deb Nath ${ }^{2 *}$ \\ Mohd. Mejbahul Bahar ${ }^{3}$ \\ Ashraful Alam ${ }^{4}$ \\ Juthi Bhowmik ${ }^{5}$
}

'Department of Surgery

Bangabandhu Sheikh Muiib Medical University (BSMMU) Dhaka, Bangladesh.

${ }^{2}$ Department of Neurosurgery Bangabandhu Sheikh Muiib Medical University (BSMMU) Dhaka, Bangladesh.

${ }^{3}$ Department of Surgery

General Hospital

Munshigani, Bangladesh.

${ }^{4}$ Department of Surgery

Upzilla Health Complex, Mirzapur

Tangail, Bangladesh.

${ }^{5}$ Department of Obstetrics \& Gynecology Ad-Din Medical College Hospital Dhaka, Bangladesh.

\begin{abstract}
Background: Breast cancer results from uncontrolled proliferation of malignant cells resulting appearance of a lump or a mass in the breast. Although many epidemiological risk factors have been identified, the cause of any individual breast cancer is most often unknowable. A women's reaction to any suspected disease of breast may include fear of disfigurement, loss of sexual attractiveness and death. Social and religious factors, unawareness of fatality of the disease, fear of infertility hinder early diagnosis \& treatment. Early diagnosis is the key to increased survival. Objective: To find out clinical presentation for breast cancer. Study design: It is a prospective study of 50 carcinoma breast patients who palpable breast lump. It was conducted during the six months period. Data were collected pre-designed data collection sheet. Data were analysis statistical package for social science (SPSS) program. Result : Most of the malignant lesions are above the age of 40 years and peak incidence are between 41-50 years and most of patients under this study were in advanced stage-III (54\%) and stage-IV (22\%). Patients were presented as nipple discharge $(20 \%)$, pain in the breast $(26 \%)$, ulceration over the lump $(14 \%)$, paeu'd orange (10\%) skin fixation over the lump (18\%), fixation to the chest wall (14\%) nipple retraction $(22 \%)$. Among the 50 patients there was only one male ca-breast patient $(2 \%)$. Among the histopathological types infiltrating duct cell carcinoma (NST) were $41(82 \%)$, ductal carcinoma in situ $6(12 \%)$, lobular carcinoma invasive 2 (4\%), lobular carcinoma in situ $1(2 \%)$ and carcinoma involved in different quadrants were upper \& outer 21 (42\%), lower outer 5 (10\%), upper and inner $12(24 \%)$, lower and inner $4(8 \%)$, central $7(14 \%)$ and breast as a whole involvement was $1(2 \%)$. About the involvement of carcinoma breast, left breast involvement were $52 \%$, right breast $46 \%$ and bilateral involvement was $2 \%$. Conclusion: This prospective study shows an alarming high incidence of carcinoma breast with palpable breast lump. The diversity of clinical presentation of breast lumps in different age group were observed is our hospital practice. This study gives an idea about the incidence of various types of lesions of breast in different age groups in our country.
\end{abstract}

Key words : Breast cancers; lump; malignant cell.

\section{INTRODUCTION}

Breasts are modified sweat gland and functionally of great importance for the offspring as the benefits of breast feeding are many fold. For the woman herself breasts are symbol of womanhood and significant components of feminine beauty. Breast is also dynamic structure that undergoes changes throughout women's reproductive life. This changes involve disturbances in the breast physiology extending from an extreme of normality to well defined disease process.

One fourth women suffer from breast disease in their life time after puberty ${ }^{1,2}$. Worst of all it becomes a cause of death among female population in the form of breast cancer which is most common cancer and second leading cause of cancer death of women after 30 years of age in USA and Western World ${ }^{3-4}$. 
This malignancy can plauge a mother, a sister, a wife, or a daughter and thus has wide familial implications. Breast cancer results from uncontrolled proliferation of malignant cells resulting appearance of a lump or a mass in the breast. In western world breast cancer accounts for $27 \%$ of all female cancer and one out of 14 women can expect to develop breast cancer in their life time ${ }^{5-6}$. There are considerable variation in breast cancer incidence, which is particularly low in developing countries and $\operatorname{Japan}^{7-8}$.

In Bangladesh though there is no exact statistics about the incidence of breast carcinoma in females, appreciable number of patient suffer from breast cancer with poor outcome due to late presentation, diagnosis and treatment. A number of studies have been undertaken on carcinoma breast in this country. This study is being carried out to determine the incidence of carcinoma in cases of breast lumps presenting in tertiary hospitals.

\section{MATERIALS \& METHODS}

It is a prospective study carried out in different surgical units of tertiary level hospital. Total 50 patients were admitted in different surgical units of tertiary level hospital with clinical diagnosis of Breast Carcinoma for elective surgery. Patients were selected randomly irrespective of age who definite palpable or doubtful Breast lumps. Detailed history of each patient under study were recorded with special attention to history of Breast cancer in their family, their age of menarche, lactating history, menopausal status \& use of oral contraceptives. Important and relevant findings on thorough physical examination will be recorded. Collected data were analysed to find out the risk factors, clinical presentation \& age incidence of breast cancer in our country.

\section{RESULTS}

Table 1: Demographic characteristics of patients $(n=50)$

$\begin{array}{lcc}\text { Age (Years) } & \text { Number of patients } & \text { Percentage }(\%) \\ 11-20 & 0 & 0 \\ 21-30 & 03 & 6 \\ 31-40 & 15 & 30 \\ 41-50 & 24 & 48 \\ >50 & 08 & 16 \\ \text { Sex } & & \\ \text { Male } & 01 & 2 \\ \text { Female } & 49 & 98\end{array}$

Most of the malignant lesions are above the age 40 years and peak incidence in between 41-50 years. Most of the breast malignancies occur in female patients.

Table 2: Clinical presentation of the disease $(n=50)$

$\begin{array}{lcc}\text { Presenting features } & \text { Number of patients } & \text { Percentage (\%) } \\ \text { Lump in the breast } & 50 & 100 \% \\ \text { Pain in the breast } & 37 & 74 \% \\ \text { Nipple discharge } & 10 & 20 \% \\ \text { Ulceration over lump } & 11 & 22 \% \\ \text { Peau'd orange } & 8 & 16 \% \\ \text { Skin fixation over lump } & 9 & 18 \% \\ \text { Fixation of lump to chest wall } & 7 & 14 \% \\ \text { Nipple retraction } & 13 & 26 \%\end{array}$

In the study $100 \%$ patients presented with breast lump of the total 50 patients, next down word successive presenting feature were pain in the breast $74 \%$, nipple retraction $26 \%$, ulceration over the lump $22 \%$, nipple discharge $20 \%$, skin fixation over lump $18 \%$, peau'd orange $16 \%$ and fixation of lump to chest wall $14 \%$.

Table 3: Involvement of the breast by primary lesion $(n=50)$

\begin{tabular}{lcc} 
Breast involvement & Number of patients & Percentage $(\%)$ \\
Right & 23 & $46 \%$ \\
Left & 26 & $52 \%$ \\
Bilateral & 1 & $2 \%$ \\
\hline
\end{tabular}

Table shows of the total breast lesion, bilateral involvement was rare.

Table 4: Histological types of carcinoma breast lump $(n=50)$

\begin{tabular}{lcc} 
Histological types & Number of patients & Percentage (\%) \\
Infiltrating duct carcinoma & 46 & $92 \%$ \\
Mucinous carcinoma & 2 & $4 \%$ \\
Medulary carcinoma & 1 & $2 \%$ \\
Tubular carcinoma & 1 & $2 \%$ \\
Papillary carcinoma & 1 & $2 \%$ \\
\hline
\end{tabular}

Among the commonest malignant lesions infiltrating duct carcinoma was more common and second highest common lesion was Mucinous carcinoma.

Table 5: Carcinoma involved the different quadrant of the breast $(n=50)$

\begin{tabular}{lcc} 
Quadrant involved & Number of patients & Percentage (\%) \\
Upper \& outer quadrant & 21 & $42 \%$ \\
Upper \& inner quadrant & 12 & $24 \%$ \\
Lower \& outer quadrant & 5 & $10 \%$ \\
Lower \& inner quadrant & 4 & $8 \%$ \\
Central & 7 & $14 \%$ \\
Whole breast & 1 & $2 \%$ \\
\hline
\end{tabular}

Among two involved highest sites $42 \%$ was upper and outer quadrant and $2^{\text {nd }}$ highest was $24 \%$ upper and inner quadrant.

Table 6: Presentation of carcinoma breast according to stage (IUAC)

\begin{tabular}{lcc} 
& Number of patients & Percentage $(\%)$ \\
Stage-I & 5 & $10 \%$ \\
Stage-II & 7 & $14 \%$ \\
Stage-III & 27 & $54 \%$ \\
Stage-IV & 11 & $22 \%$ \\
\hline
\end{tabular}

Most of the patients under study were in advanced stage (III \& IV), only $10 \%$ patients were in stage-I and $14 \%$ patients were in stage-II. 


\section{DISCUSSION}

Breast cancer is one of the most common cause of death in case of female. Its is estimated that the world burden of breast cancer is i million women newly diagnosed each year. In our country there is no relevant clear cut data about the incidence of breast carcinoma. But number of new cases in each hospital is not uncommon. In this small scale study breast carcinoma is seen common in $5^{\text {th }}$ decade ( $41-50$ years) $48 \%$. The socio economic status of most of the patients is poor. Most of the patients have no positive family history. They started menstruation on an average age of 11 years and were menopausal at the average age of 46 years. Most of the patients are illiterate and they do not know about the breast cancer. So they suffered at the early stage of the disease and came to the hospital at the advanced stage of the disease i.e when significant symptoms are produced such as pain, discomfort, skin changes or and increase in size of the lump. The reasons and little data could be basis of higher incidence of carcinoma observed in out country as compared to the west.

In the present work, the incidence of breast carcinoma increases gradually with the age $00 \%$ in $2^{\text {nd }}$ decade to $48 \%$ in $5^{\text {th }}$ decade of life. This finding is coherent with study at united states by west and EI tanner in which no case of carcinoma was reported in $2^{\text {nd }}$ decade of life. Only 3 cases $(6 \%)$ of carcinoma were diagnosed in $3^{\text {rd }}$ decade. The incidence of $6 \%$ in the present study is much higher than $2.5 \%$ observed by palmer, $2 \%$ by Donegan and $1 \%$ by Raju et al. ${ }^{9}$ in their study. The incidence of malignancy was $23.2 \%$ and $38.9 \%$ in the $4^{\text {th }}$ and $5^{\text {th }}$ decade respectively which was also observed by Salina and Usmani at Lahore. The incidence of malignancy as observed by Donegan and Bennette, UK was $21 \%$ and $15 \%$ respectively in the $4^{\text {th }}$ decade and $30 \%$ in the $5^{\text {th }}$ decade as reported by Donegan.

The peak incidence of carcinoma breast observed by Usmani et $\mathrm{al}^{10}$. in the $4^{\text {th }}$ decade is almost similar to that of this study. This indicates carcinomas in breast lumps are more common at early age in our setup. In a similar study done by Malik et $\mathrm{al}^{7}$. on 50 patients, the age distribution was between 15 and 65 years and the maximum patients were seen in the 31 to 40 years group. Similar study done by Yusuf et $\mathrm{al}^{3}$. Ahmed et $\mathrm{al}^{6}$. showed similar age patterns.

Lump was the presenting features of all the cases in this series. Lumps were mild to moderately painful in $26 \%$ cases. In rest of the cases there were no complaints of significant pain. Nipple discharge was present only in $20 \%$ of patients where most of the patients present with blood stained discharge. Nipple retraction was present in $22 \%$ patients. All of them were diagnosed as breast carcinoma according to histopathological report. All the patients detected the lump by themselves. Parveen et $\mathrm{al}^{11}$. who analysed breast lesion found that $95 \%$ of their patients presented with breast lump, 5\% with nipple discharge and 5\% with pain. Except high incidence of painful lump in this study, the findings were more or less similar to those of Parveen et $\mathrm{al}^{11}$.
Among the histological types of breast carcinoma 41 (82\%) patients are duct cell carcinoma (NST), $6(12 \%)$ patients are ductal carcinoma in situ, 2 (4\%) patients are lobular carcinoma invasive and $1(2 \%)$ patients lobular carcinoma in situ. No patients were diagnosed as a case of medullary, papillary and metaplastic carcinoma. Out of 50 clinically suspected breast malignancy, $5(10 \%)$ patients were in stage-I, $7(14 \%)$ patients were in stage-II, 27 (54\%) in stage-III and $11(22 \%)$ patients were in stage-IV. So, most of the patients were in advanced malignancy.

Involvement of breast by primary lesion, left breast malignancy were $52 \%$ and right sided carcinoma breast were $46 \%$ where as bilateral involvement were only $2 \%$. In their series, Malik et $\mathrm{al}^{7}$. showed left breast involvement in 27 patients $(54 \%)$ while right breast $23(46 \%)$. This result is very much similar to my study.

The upper and outer quadrant was the commonest site of the lump in our patients $21(42 \%)$ patients while the upper inner quadrant was involved in $12(24 \%)$ the lower and outer in 5 $(10 \%)$ and inner quadrant in $4(8 \%)$. Malik et $\mathrm{al}^{7}$. in his series had 29 patients $(58 \%)$ with a lump in the upper and outer quadrant and 9 had a lump in the upper and inner quadrant while 4 patients had a palpable lump in the lower and outer quadrant. There were 5 and 3 patients the upper and outer quadrant to be the dominant quadrant to have a palpable lump. About sex distribution of the carcinoma breast in this study showed only one (2\%) male patients of carcinoma breast. Men have a lower risk of developing breast cancer (approximately 1.08 per 100,000 men per year), but this risk appears to be rising. Men with gvnaecomastia do not have a higher risk of developing breast cancer. There may be an increased incidence of breast cancer in men with prostate cancer. The prognosis, even in stage I cases, is worse in men than in women. The treatment of men with breast cancer is similar to that in older women. Since the male breast tissue is confined to the area directly behind the nipple, treatment for males has usually been a mastectomy with axillary surgery. This may be followed by adjuvant radiotherapy, hormone therapy (such as tamoxifen), or chemotherapy.

\section{CONCLUSION \& RECOMMENDATION}

This study shows most common clinical presentation were pain in the breast, nipple retraction, ulceration over the lump, nipple discharge, skin fixation over lump, peau'd orangeand fixation of lump to chest wall. The breast is the most common site of cancer in women. The probability of developing breast cancer increases with age, throughout life. So measures aimed at early detection and proper treatment is required. Women who are at greater than normal risk of developing breast cancer, should be identified by proper health education and employing screening program by regular self examination, of breast, physical examinations by doctors. Any suspicious lesion must have a cytological diagnosis. Considering the cost benefit ratio a less expensive screening technique should be implemented. Better health education along with seminar \& symposium locally or nationally and well publicity by radio, TV, newspaper, mobile phone, website and others electronic media women will more conscious and that will help then to realize about the disease.

\section{DISCLOSURE}

All the authors declared no competing interest. 


\section{REFERENCES}

1. Siddique, Imtiaz RM, Pattern of breast disease, preliminary report of breast clinic J Coil physician Surg. Pak. 2001; 11: 497-500.

2. Ghurnro AA, Khaskheli NM, Monien AA, Ansari AG, A Wan MS, Clinical profile of patient with breast cancer. J Coil physician Surg. Pak. 2002; 12: 28-31.

3. Yusuf A Khan JS, Bhopal FG, Iqbai M, Minhas S, Mahrnood N, et al. Level of awareness about breast cancer among females presenting to a general hosp. in Pakistan J. Coil physician Surg. Pak. 2001; 11: 131-5.

4. Berg JW, Hutter RV, Breast cancer 1995; 75: 25 7-69.

5. Sauncliss CM, Baurnm. The breast in: Russell RCG, Willarns NS, r Buistrode CJK editors, Bailey \& loves short practice of surgery $25^{\text {th }}$ ed. London: Arnold 2000; 749-772.

6. Ahmed M, Khan AH, Mansoor A. The pattern of malignant tumours is Northern Pakistan J. Pak. Med Assoc 1991; 41: $270-273$.

7. Malik IA, Khan WA, Khan ZK, Pattern of malignant tumours observed in the University Hospital, a retrospective analysis, J Pak Med Assoc 1998; 48: 120-122.

8. Rasool A, Malik KI, Luqman Ml Clinopathological study of carcinoma of breast. Pak J Med Res. 1987; 26: 135-139.

9. Raju GC. Jankey N. Narynsingh V. Breast disease is young west Indian Women; an analysis of 1051 consecutive cases. Posgraduate Med. J. 1985;61:977-978.

10. Usmani K, Khanum A. Afzal H, Ahrned N. Breast carcinoma is Pakistani women. J Environ Pathol Toxicol oncol 1996; 15:25 1-3.

11. Parveen S, Shahid MA. Prognostic factors in stage-I breast cancer: a prospective study. J Pak Med Assoc. 1997; 47:117-118. 